\title{
How To Write A Correct Death Certificate And Why?
}

\author{
Dr. Sujan Narayan Agrawal \\ Department of Surgery, late brkm Government Medical College, Jagdalpur (Bastar) C.G. \\ Pandit Deendayal Upadhyaya Smriti Swasthya Vigyan Avum Ayush Vishvavidyalaya, Raipur Chattisgarh
}

\begin{abstract}
Death is the cessation of life and the existence of an individual. With the advancement in cardiopulmonary resuscitation, life support system and in the era of organ donation, the precise definition of death has become more complicated. The most appropriate definition is "irreversible cessation of circulatory and respiratory functions and also irreversible cessation of all functions of brain including the brain stem". The death can be described as somatic death, and/or molecular death. The somatic death is the clinical death; the individual cells of the body take time to die i.e. molecular death. Issuing the death certificate is the duty of every registered medical practitioner. The death certificate is a standard proforma (form No. 4), devised by world Health Organization (WHO) and is implemented by Govt of India. This form is devised for the sake of uniformity and comparability of data. Filling up of the form requires utmost care and knowledge of morbid events leading to the death of a person. This certificate is also required for the cremation or burial of body. It is a legal document too. This article is aimed to guide and sensitize the registered medical practitioner about the importance and correct manner to fulfil the entries in death certificate.
\end{abstract}

Keywords: Death certificate, Somatic death, molecular death, registration of birth and death act.

\section{Introduction}

Death is the cessation of life and the existence of a person. There are many definitions of death, which emphasises, cessation of respiratory function and circulation as the main parameter of death and for the declaration of a person dead. With advancement in cardiopulmonary resuscitation (CPR), ventilators and other life support systems, the actual definition of death has become complicated. The physician's concept of death is total stoppage of circulation of blood with consequent cessation of vital functions. All these definitions require revision from cessation to permanent cessation of respiration and circulation. Therefore a more appropriate definition would be "death is a permanent and irreversible cessation of functions of three interlinked vital systems of body namely the nervous, circulatory and respiratory systems, the so called tripod of life. [1].

This definition is also incomplete since it does not recognise the concept of brain death and utility of life sustaining aids and equipments. In 1980 a model definition of death was put forth by representative of American Bar Association and the National conference of commissioner of uniform state law as [2][3].

"An individual who has sustained either (I) Irreversible cessation of circulatory and respiratory function or (II) Irreversible cessation of all functions of the entire brain including the brain stem is dead".

The model definition is complete and elaborate. It recognises the concept of brain death and death by cardio pulmonary arrest. It also acknowledges the concept and utility of life sustain aids and equipments. There are statutory definitions too as below:-

1. Section 46 of Indian Penal Code states that "the death denotes the death of a human being unless the contrary appears from the context.

2. section 2(b) of the registration of Birth and Death act 1969 defines death as "Permanent disappearance of all evidence of life at any time after live birth has taken place."

\subsection{Somatic death}

\section{Somatic and Molecular Death.}

The death can also be described as somatic and molecular death. The somatic death is the clinical death or systemic death. This corresponds with physical stoppage of functions of heart, lung and brain. It indicates the demise of a person and it entitles the registered medical practitioner to certify that the death has occurred. [4]. Thus the legal definition of the death depends upon the diagnosis of somatic death. [5].

\subsection{Molecular/Cellular death}

Even after the somatic death, the individual cells of the body may not die immediately and still respond to chemical, thermal and electrical stimuli, for example, pupil may contract on application of myotic drugs. The cellular death entails death of the individual cells of different tissues and organs.

The gap between somatic and cellular death is important because fallowing reasons:-[6]. 
2.2.1. Disposal of body- Even after the somatic death, there may occur, the spontaneous movement of the muscles. The layperson may perceive it as sign of life and may blame the attending physician for declaring a live person, dead.

2.2.2. Molecular death occurs, after somatic death. In this period between somatic and molecular death, organs from dead body can be retrieved for the purpose of organ transplant. Thus this gap is useful for cadaveric organ transplant.

Death of an individual has got many medico legal implications. The death has to be declared by the attending physician, who has to issue a death certificate. After issuing a death certificate, the relatives can dispose the dead body according to their faith and religion. If the cause of death is suspicious, death certificate should not be issued and body is handed over to the police for post mortem. The cadaveric organ transplant and removal/retrieval of organ from dead body cannot be done unless a person is certified to be dead.

\section{The Death Certificate: A Vital Document}

The death certificate is an important and vital document because of fallowing reasons:-

3.1. It is an important legal document which certifies the death of a person.

3.2. It explains the cause, manner, mode and time of death.

3.3. It is required before obtaining permission for cremation or burial from municipal authorities.

3.4. A properly registered certificate is essential for claims of various dues like insurance, gratuity, provident fund, family pension, and accident benefit claims etc.

3.5. for execution of the will of the deceased.

3.6. for claims of movable and immovable properties.

3.7. Deletion of the name of the deceased person's name from ration card, shares, movable and immovable properties, bank account etc.

3.8. It is a vital document for the Government also, because [7]

(I) it is a basis of mortality data, required to assess the effectiveness of health policies.

(II) To provide feedback from such health policies.

(III) For proper health planning and implementation.

(IV)To decide the priorities for health and medical research programmes.

\section{Pre Requisite For Issuing A Death Certificate}

4.1. It is issued free of charge. [Registration of Birth and death Act 1969.section 10 (3).]

4.2. Only a single copy of death certificate is issued. The doctor/hospital should retain a carbon copy of Certificate.

4.3. It is the duty of registered medical practitioner or medical officer in charge of the hospital, to give information to the registrar of birth and death occurring in hospital as per the Registration of Birth and death Act, section 8(b). [8]

4.4. Any medical practitioner who refuses, to give, or issue a certificate under subsection 3 of section (10) of Registration of Birth and Death act 1969 shall be punished with fine which may extend to fifty rupees. [Section 23(3)].

\subsection{It is issued by the registered Medical practitioner}

(I) Who has been the medical attaindent during the deceased life.

(II) Has attended the patient at least once during the seven days preceding death. [As recommended by the Brodrick committee].

(III) He is satisfied with the cause of death.

4.6. Death certificate is necessary even in cases of death that are stillborn/ premature.

4.7. The doctor should not sign the certificate blank, leaving the details to be filled by someone else.

4.8. No certificate to be issued in case of sudden death of a person who has not been attended by the doctor before his/her death.

4.9. In partnership practice one doctor should not certify the case of his colleague patient, unless attended the deceased in past.

4.10. No certificate is issued in death, which is unexpected, unexplained and death under suspicious circumstances.

4.11. The death of a people under the custody of police or those residing in public institutions like remand home, asylum, hostel, under medical procedure etc are reported to police/coroner and are subjected to post mortem. 


\section{The standard proforma}

For ensuring the National and International comparability, it is necessary to have a uniform and standardised system of recording and certifying deaths. For the same purpose death certificate recommended by WHO is used. The International classification of disease should be used in death certificates, whenever possible for uniformity, maintenance and fast retrieval of data through computerization. The death certificate recommended by WHO is as follows (FORM NO. 4)

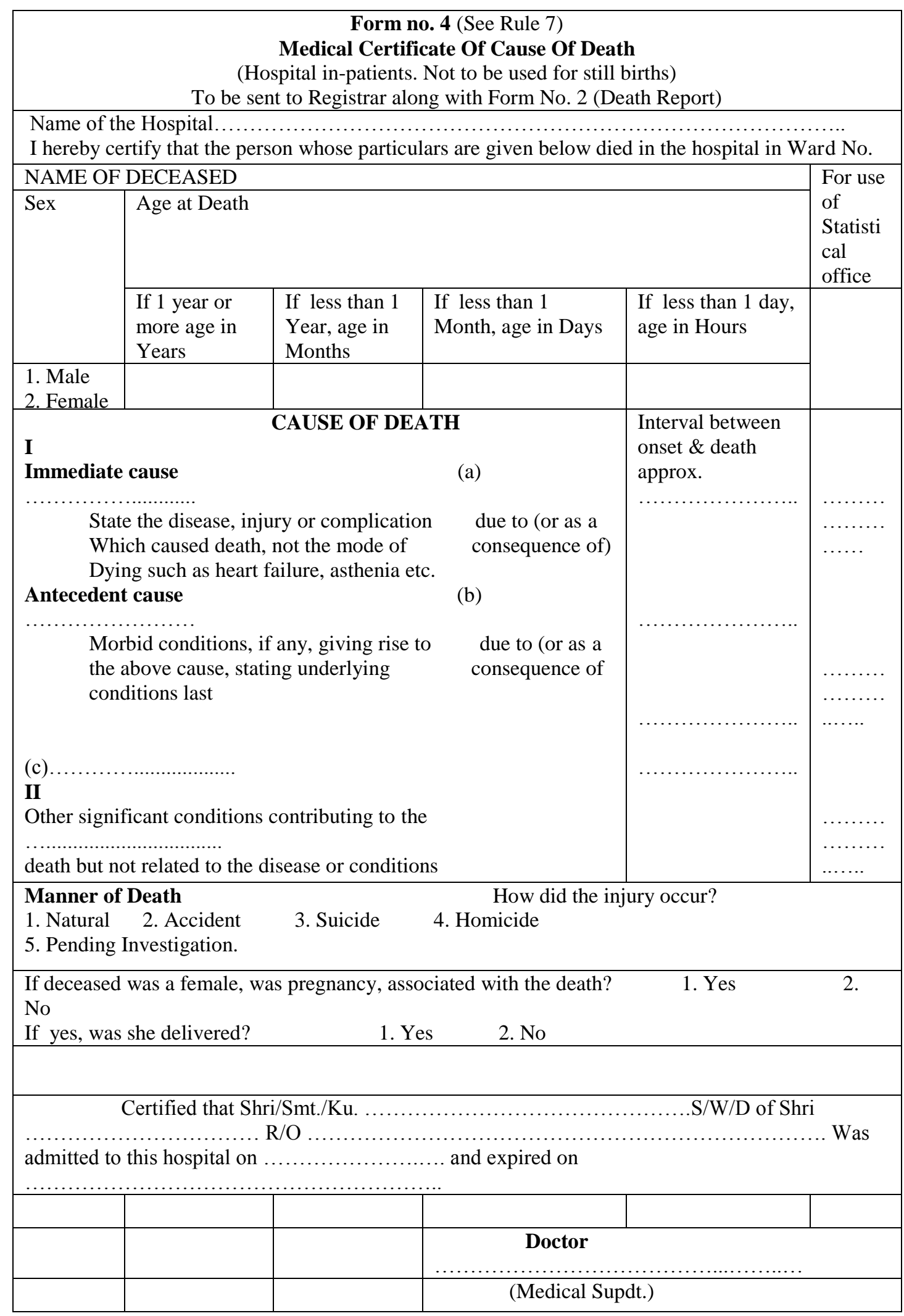




\begin{tabular}{|l|l|l|l|}
\hline & & & Name of Hospital) \\
\hline & & & \\
\hline & & & \\
\hline
\end{tabular}

\section{How to fill up the death certificate}

Name of the deceased: to be given in full. Do not use the initials. If the deceased is an infant, not yet named, at the time of death, write son of $(\mathrm{S} / \mathrm{O})$ or daughter of $(\mathrm{D} / \mathrm{O})$, followed by the names of mother and father.

Age: If the deceased is over one year of age, give age in complete years. If the deceased was below one year of age, give age in months and if below one month of age, in completed number of days, and if below one day, in hours.

Cause of death: this part of the form should always be completed by the attending physician personally. The actual certificate is divided in two parts viz. part-I and part-II.

Part-I. It Deals with the immediate cause and the underlying cause of death. The immediate cause or the terminal event is entered here.

Part-II. It Deals with other significant condition or disease contributed to the process of death but did not lead to it.

Part-I.

Only one cause is to be entered in each line.

Line-a: Immediate cause of death is entered here, like disease/abnormality/injury/poisoning etc. The immediate cause is defined as the immediate or terminal event leading to death. Mode of death such as respiratory failure, cardiac failure etc is not an appropriate entry.

Line-b: Next considers whether the immediate cause is a complication of delayed result of some other cause. If so, enter the antecedent cause in part-1 line $-\mathrm{b}$. The antecedent causes refer to the pathological process or injury responsible for death. Thus it is a disease or injury that has initiated the train of morbid events leading directly to death or it is the circumstances of the accident or violence that produced the fatal injury. [9].

Line-c: Sometimes there will be three stages in the course of events leading to death. If so, line-c will be completed.

Part-II.

Other significant conditions contributing to death, but not related to disease condition causing it.

Onset: complete the column for interval between onset and death whenever possible, even if very approximate e.g. from birth, or several years etc.

\subsection{Examples Clinical causes}

6.1.1. The death due to myocardial infarction as a result of coronary occlusion as a consequence of atherosclerosis.

6.1.2. Death due to peritonitis as a result of perforation as a consequence of duodenal ulcer.

6.1.3. Death due to chronic renal failure, as a result of hypertension as a consequence of polycystic kidney disease.

6.1.4. Death due to uraemia as a result of retention of urine as a consequence of prostatic hypertrophy.

6.1.5. Death due to emaciation as a result of metastasis of lymph nodes and liver as a consequence of bronchogenic carcinoma of lung.

Medico- legal causes.

6.1.6 Death due to asphyxia as a result of constriction of neck as a consequence of hanging/strangulation.

6.1.7. Death due to cerebral ischemia as a result of occlusion of carotid arteries as a consequence of throttling.

6.1.8. Death due to asphyxia as a result of aspiration of fluid in air passage as a consequence of wet drowning.

6.1.9. Death due to shock and haemorrhage as a result of rupture of spleen as a consequence of blunt injury of (left) hypochondriac region.

6.1.10. Death due to shock and haemorrhage as a result of fracture of middle meningeal fossa as a consequence of head injury.

6.1.11. Maternal deaths: Ensure to answer the question on pregnancy and delivery. This information is needed for all women of child bearing age, even though the pregnancy has nothing to do with the death.

\section{The sequence of events to be fallowed, in death certification. [10]}


A) The cause of death is known.

7.1. Death of a person- the attending physician/registered medical practitioner issues the death certificate, in prescribed proforma. It is as per provision made in the Registration of Birth and Death 1969 (18 of 1969.).[8]

7.2. The certificate is send to Registrar of Birth and Death. (As per above Act)

7.3. Registrar or his representative certifies the extract given in the certificate.

7.4. This certified death certificate is admissible as evidence for the purpose of proving birth/death. (Section 76, of Indian Evidence Act 1872 (1 of 1872).

B) The cause of death is not known/ uncertain.

7.5. The last attending doctor does not issue the death certificate.

7.5.1 The case is informed to the police.

7.5.2. The body is kept in safe custody and handed over to the police for autopsy.

7.5.3. After autopsy the facts of death is communicated to local registrar.

7.5.4. Death certificate is issued by registrar of Birth and Death.

C) Miscellaneous issues.

1. Doctor many times has to face a situation where he is in dilemma whether to issue death certificate or not, particularly when party is known and he has not attended the case before death. A proper explanation and guiding the relatives will help to cope up with the situation.

2. The code of medical ethics permits the disclosure of fact that the deceased was suffering from HIV/AIDS infection. This exception to code of medical ethics is permitted in public overriding confidentiality.

\section{References}

[1]. Nandy A, death and post-mortem changes in Principles of forensic medicine (Calcutta: New central book agency ltd, 2005) 133-73.

[2]. Peper JA, Time of death and changes after death. Part-1: anatomical considerations, in Spitz Wu (ed) Spitz and fisher's medico legal investigation of death. $3^{\text {rd }}$ edition (USA: Charles $\mathrm{C}$ Thomas publishers, 1993) 14-50.

[3]. Fauci AS, Braunwald E, Isselbacher KJ, Wilson JD, Martin JB, Kasper DL, Hauser SL, Longo DL (eds), in Harrison principles of internal medicine Vol-1, $14^{\text {th }}$ edition (New-York: Macgaw-hills 1998) 1-6.

[4]. Gordon I, Shapiro HA, The diagnosis and the early signs of death. Phenomena that occurs after death, in Forensic medicine- A guide to principles, $2^{\text {nd }}$ edition (Edinburough: Churchill living stone 1982). 1-63.

[5]. Dikshit PC, Moment of death, in textbook of forensic medicine and toxicology $1^{\text {st }}$ edition, (New Delhi: Peepee publishers and distributors (P) ltd. 2007) 35-46.

[6]. Parikh CK, Medico legal aspects of death, in Parikh textbook of medical jurisprudence and toxicology. $5^{\text {th }}$ edition (CBS publishers, 1995).

[7]. Physician's manual on medical certification of cause of death, $4^{\text {th }}$ edition. Vital statics division. Office of the registrar general of India (New Delhi: Ministry of home affairs, 2000). 130-79.

[8]. Arora k, the registration of Birth and Death Act 1969 (18 of 1969) (New Delhi: Professional book publishers 2007)

[9]. Park K, principals of epidemiology and epidemiological methods, in Park's textbook of preventive and social medicine, $14^{\text {th }}$ edition (Jabalpur M/S Banarsidas Bhanot publishers, 1995) 45-106.

[10]. he registration of birth and death act, 1969 (18 of 1969) (New Delhi Universal law publishing Co. Pvt Ltd 2006) 6-8. 